\title{
Pimping: Valuable Teaching Tool or Mistreatment? Perceptions of Medical Students and Faculty Differ
}

\author{
Anthony Duncan*, MD; Bridger Rodoni ${ }^{\dagger}, \mathrm{BSc}$; \\ Nicole Pescatore ${ }^{\ddagger}, \mathrm{MPH}$; Steve Kasten ${ }^{\S}, \mathrm{MD}, \mathrm{MHPE}$
}

\section{Importance}

The AAMC Graduate Questionnaire has drawn attention to medical student mistreatment. Pimping, a form of Socratic teaching often used in medical education where students are singled out by faculty for questioning, may be considered by some students and faculty as mistreatment. To date, minimal research has been performed on the viewpoints of students and faculty regarding pimping and its relation to mistreatment.

\section{Objective}

This study aims to formally define pimping and determine if there is a difference in the perception of students and faculty on its role in medical education.

\section{Design}

Medical students and faculty of Michigan medical schools were surveyed via electronic questionnaire. Chi-squared and Fisher's exact tests were performed.

\section{Setting}

Medical schools within the state of Michigan

\section{Participants}

Students who had completed their core clerkships and faculty with experience educating medical students in a clinical setting

*University of North Dakota School of Medicine and Health Sciences, anthony.duncan@und.edu

†University of Michigan Medical School, bmrodoni@med.umich.edu

(D) https://orcid.org/0000-0002-0889-3670

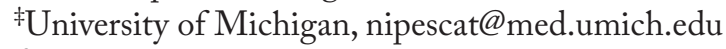

${ }^{\S}$ University of Michigan, skasten@med.umich.edu

doi: $10.3998 / \mathrm{mjm} .1435$

Conflicts of interest:

The authors have no conflicts of interest to disclose 


\section{Results}

The student response rate was $42 \%$; the faculty response rate could not be determined. The majority of students agreed with our operational definition of pimping and $100 \%$ had experienced pimping. $54 \%$ of students reported a positive experience with pimping, $26 \%$ neutral, and $20 \%$ reported a negative experience. The majority of students reported it was challenging and educational and should be used regularly. Several differences were found between students and faculty as to why faculty use pimping. Students' perception of their role on the clinical care team influenced their perception of pimping as mistreatment, and students reported pimping made them feel more a part of the team.

\section{Conclusion and relevance}

This study helps to define pimping and sheds more light on the perceptions of pimping from students and faculty and their differences. Most medical students report a benefit from pimping, even though it may be stressful, and suggest it should be used regularly, which is in contrast to faculty opinion. Pimping may make students feel more a part of the clinical care team, but their role on the team may not influence whether they perceive it as mistreatment. Our data suggest medical schools should educate students and faculty on pimping and not move toward discouraging or banning it.

\section{Keywords}

medical education $\bullet$ Socratic teaching $\bullet$ pimping $\bullet$ wellness $\bullet$ clinical education

\section{Introduction}

Implementation of the Association of American Medical Colleges (AAMC) Medical School Graduation Questionnaire (GQ) in 1978 started to reveal how often medical students experience mistreatment in the clinical setting. Since its initiation, medical students continue to report mistreatment when filling out the survey, with the highest prevalence in the clinical setting on surgery and ob/gyn clerkships. ${ }^{1-4}$ Recent studies have suggested that the GQunderrepresents actual mistreatment. ${ }^{5,6}$ This is a concern for educators as data suggest mistreatment affects medical students' learning environment, self-esteem, and career choices. ${ }^{2,7-9}$ Accordingly, schools seek to identify and address conditions and curricular elements that are or may be perceived as mistreatment.

Brancati published "The Art of Pimping" in $1989,{ }^{10}$ which drew attention to this commonly used method of medical education and generally defined it as asking questions to a single individual based on the subject at hand. Since Brancati's paper, several authors have discussed the utility of pimping. ${ }^{11-16}$ However, few studies have aimed to formally define pimping and investigate the specific viewpoints of students and faculty. Wear et $\mathrm{a}^{17}$ performed a focus group to analyze the perception of pimping among medical students. They found that the majority of students did not view pimping to be malevolent as they defined it. Pimping often involves being singled out by an instructor for direct questioning. Since being singled out may be viewed negatively by students and perhaps by some as mistreatment, some medical schools are discouraging its use, despite a lack of evidence on its effects. With many medical schools currently implementing curriculum changes, it is logical to investigate the impact of pimping in the clinical setting. ${ }^{18-22}$

Using the work done by Wear et al, Williams et $\mathrm{al}^{23}$ surveyed pharmacy students and found no significant difference between the number of students who liked or disliked pimping. However, students and faculty in this study differed in their perceptions of why pimping was used. 
While students believed questions were being asked in a more malevolent manner, faculty considered them educational.

The present study aims to examine the viewpoints on pimping from fourth-year medical students and faculty across medical schools in Michigan. We hypothesized that there would be a significant difference in the viewpoints on pimping between students and faculty. We further hypothesized that students would perceive a benefit from pimping on their understanding and recall of information and that their perception of pimping as mistreatment would be related to their perception of the importance of their role in the patient care team.

\section{Methods}

\section{IRB, Study Design, and Questionnaire Distribution}

This study was classified as exempt by the University of Michigan institutional review board (HUM00146515). The questionnaire for this study was modeled after that of Williams et $\mathrm{al}^{23}$ which assessed the viewpoints of pharmacy school students and faculty on pimping. Additional items were added to address our hypotheses and other possible variables unique to the medical education environment. The initial questionnaire was piloted within the target populations and revised for clarity where needed. The final questionnaire was 32 items and is included as Appendix 1. Our operational definition of pimping was presented at the beginning of the questionnaire and was identical to that of Wear et al for Socratic teaching: "Socratic teaching is a term that is often applied to teaching by questioning the student on the subject at hand. It is commonly referred to as 'pimping.' Socratic teaching is sometimes described as being singled out by an instructor for direct questioning." ${ }^{17}$ The questionnaire was distributed online via Qualtrics. We recruited subjects via email on 3 separate occasions over 6 weeks. All data were de-identified and securely stored. Four $\$ 25$ gift cards were offered via random drawing as incentive.

\section{Sampling}

The target population was all fourth-year medical students in the state of Michigan. Central Michigan University, Michigan State University, Oakland University, University of Michigan, Wayne State University, and Western Michigan University were contacted and invited to participate. Three of the 6 schools allowed us to survey their students, and 4 allowed us to survey their faculty. The sample was restricted to medical students having completed their core clinical rotations (ie, fourth-year students).

\section{Statistics and Analysis}

Chi-squared and Fisher's exact tests were performed for categorical data. Statistical significance was determined by $\mathrm{p}<0.05$. Responses were excluded from analysis if they were less than 30\% complete in regard to essential items, ie, all questions not pertaining to demographic information. Responses were grouped for analysis; eg, "slightly positive" and "very positive" combined as positive and the same for negatives.

\section{Results}

\section{Respondent Demographics}

Two hundred seventy students responded; incomplete (35 with essential items incomplete) and duplicate (10) responses were discarded, leaving 225 responses for analysis. Institutional 
affiliations were as follows: 121 (54\%) Michigan State University, 74 (33\%) University of Michigan, and 52 (23\%) Central Michigan University. Fifty-four faculty responded, with the following institutional affiliations: 23 (42\%) Michigan State University, 18 (34\%) Western Michigan University, 7 (13\%) University of Michigan, and 6 (11\%) Central Michigan University. The student response rate was $42 \%$ based on institution-reported class size. An estimated 940 students met inclusion criteria at the time of this survey, making our sample $24 \%$ of the target population. Faculty response rate could not be calculated due to institutional uncertainty or inability to report faculty numbers. For our student sample, 86 respondents (38\%) identified as male and $135(60 \%)$ as female, with an average age of 26 years. Regarding race, 149 students (66\%) self-identified as white or Caucasian, 31 (14\%) as Asian, 13 (6\%) as Black or African American, 9 (4\%) as Hispanic, and 20 (9\%) as other.

\section{Definition and Frequency of Pimping}

Of 225 student respondents, 156 (70\%) agreed with our definition of pimping, while 20 (11\%) disagreed and 43 (19\%) had not encountered this term before. In comparison, 35 faculty $(65 \%)$ agreed with our definition, 9 (16\%) disagreed, and 10 (19\%) had not previously encountered this term. All of the students had experienced pimping as defined in our study. The survey found that 203 students (90\%) experienced pimping in one-on-one and group settings, while $25(10 \%)$ only experienced it in a group setting. Seventy-six percent of students reported that they experienced this on a daily or weekly basis during clerkships. Nearly all students (95\%) witnessed someone else on their team experiencing pimping, most commonly other medical students and junior residents and rarely fellows or senior residents. From the faculty standpoint, all respondents experienced this form of teaching during some point in their medical education, either as a medical student or a resident.

\section{Attitude Toward Pimping}

Just over half of student respondents $(116 ; 54 \%)$ reported a very positive or slightly positive perception of pimping. The remainder were nearly equally divided between a neutral viewpoint $(56 ; 26 \%)$ and slightly to very negative perception of pimping $(44 ; 20 \%)$ (Figure 1$)$. There was a significant difference based on institution. University of Michigan students more frequently reported a positive perception of pimping compared to the students at other institutions ( $\mathrm{p}<0.0001)$. There was no significant difference in viewpoints based on age, gender, race, or time off before medical school. A slight majority of students $(116 ; 52 \%)$ and faculty $(28 ; 51 \%)$ indicated that pimping should be used consistently (Figure 2). In contrast, 106 students (47\%) and 21 faculty (39\%) responded that it should be used sparingly. A significant difference was found between groups for those who thought it should be avoided entirely: 3 students (1\%) vs 5 faculty $(10 \%)(\mathrm{p}=0.009)$.

\section{Students' Description of Pimping}

Figure 3 summarizes adjectives students used to describe their experiences with pimping. The two most common were "educational" $(176 ; 78 \%)$ and "challenging" $(171 ; 76 \%)$; the least common were "unfair" $(25 ; 10 \%)$ and "prideful" $(18 ; 8 \%)$. More students reported that pimping helped them recall and understand information than reported that it hindered them: 153 (68\%) and $142(63 \%)$, respectively $(\mathrm{p}<0.0001)$. 


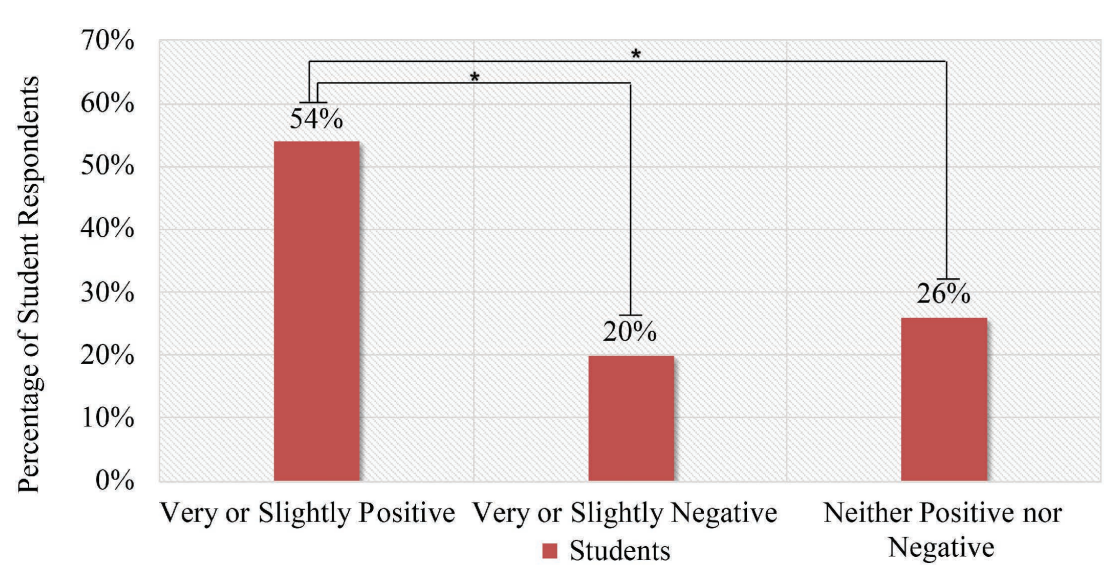

Figure 1. Students' Rating of Their Experience of Socratic Teaching

Values presented as percentage of total respondents. Student responses, $\mathrm{N}=225$ : very positive, $\mathrm{n}=33$; slightly positive, $\mathrm{n}=83$; neither positive nor negative, $\mathrm{n}=56$; slightly negative, $\mathrm{n}=33$; very negative, $\mathrm{n}=11 ; \mathrm{p}<0.001$ denoted by *

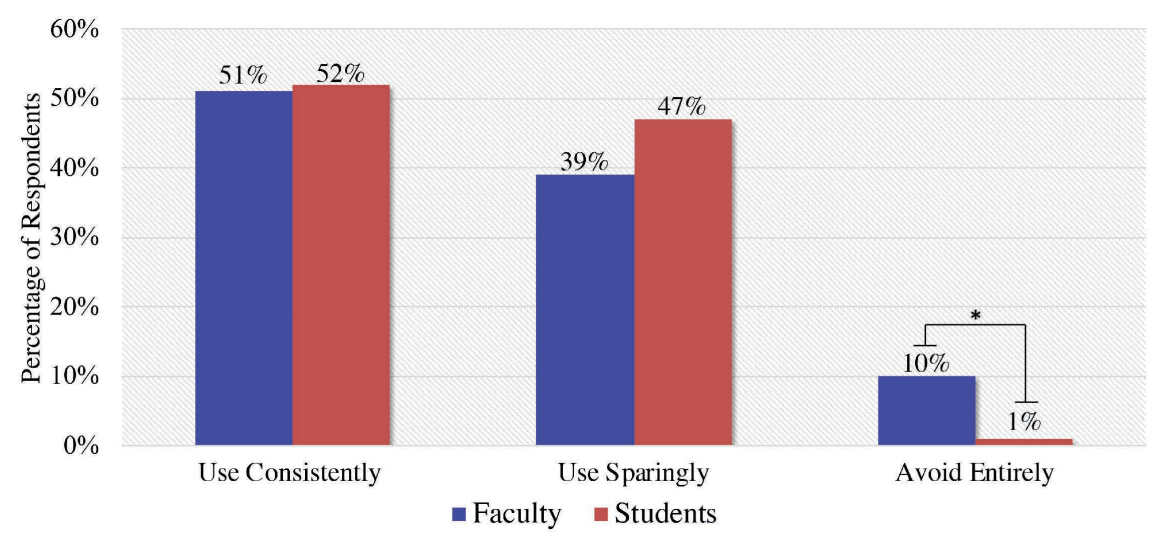

Figure 2. How Often Should Socratic Teaching Be Utilized?

Student responses, $\mathrm{N}=225$ : use consistently, $\mathrm{n}=116$; use sparingly, $\mathrm{n}=106$; avoid entirely, $\mathrm{n}=3$. Faculty responses, $\mathrm{N}=54$ : use consistently, $\mathrm{n}=28$; use sparingly, $\mathrm{n}=21$; avoid entirely, $\mathrm{n}=5 ; \mathrm{p}<0.001$ denoted by *

\section{Reasons for the Use of Pimping}

There were several significant differences in student and faculty responses regarding reasons for the use of pimping (Figure 4). Seven students (3\%) and 3 faculty (6\%) responded that it was used to suppress further questions (NS). A similar majority of each group, 148 students $(68 \%)$ and 32 faculty (82\%), responded that pimping engages students to retain their attention (NS). However, 41 students $(19 \%)$ versus zero faculty $(\mathrm{p}=0.001)$ responded that it was used to demonstrate faculty's knowledge to the students, and 38 students (18\%) versus zero faculty $(\mathrm{p}=0.002)$ responded that it was used to show that faculty are in charge. More faculty than students responded that pimping opens to broader discussion (29 (74\%) vs 90 (41\%), respectively; $\mathrm{p}<0.001)$, but fewer faculty than students responded that it reinforces teaching points 


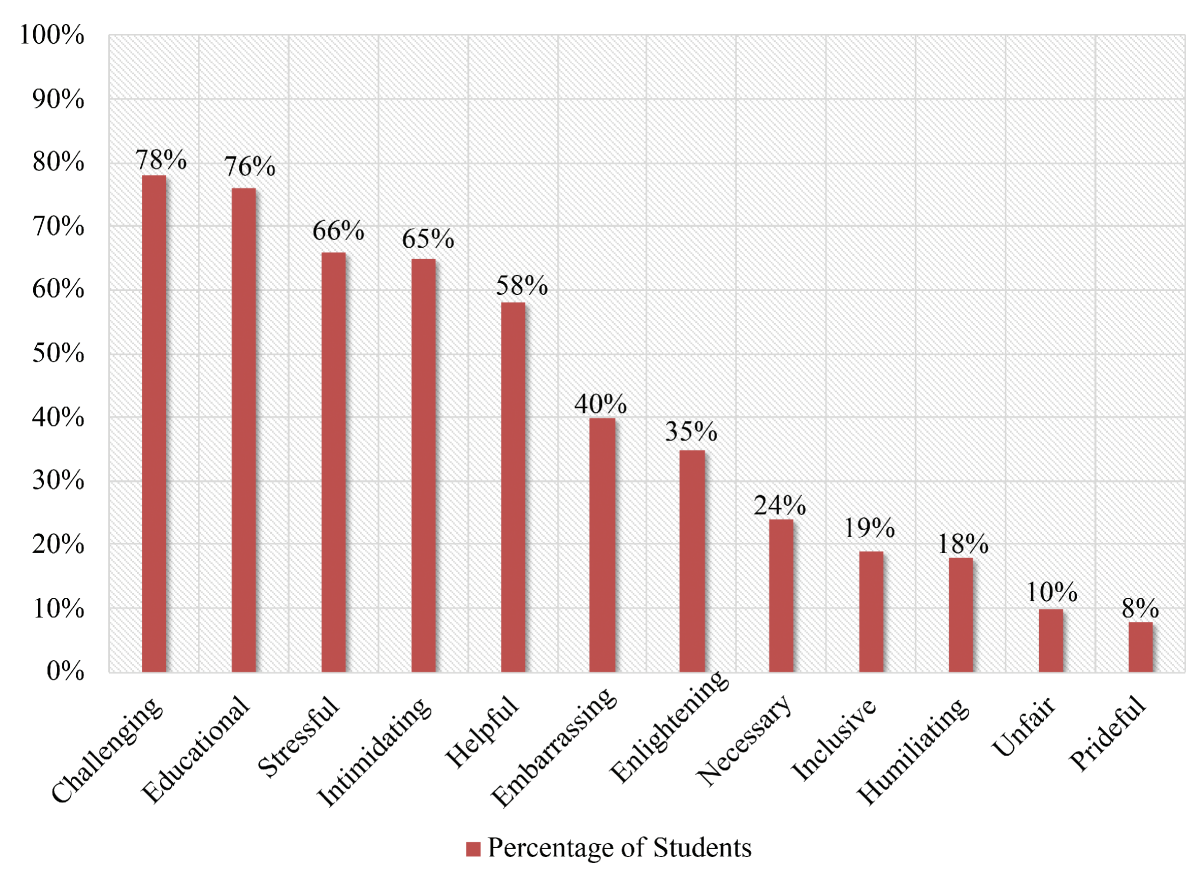

Figure 3. Adjectives Used to Describe Socratic Teaching

The 225 respondents' answers are not mutually exclusive; *denotes statistical significance.

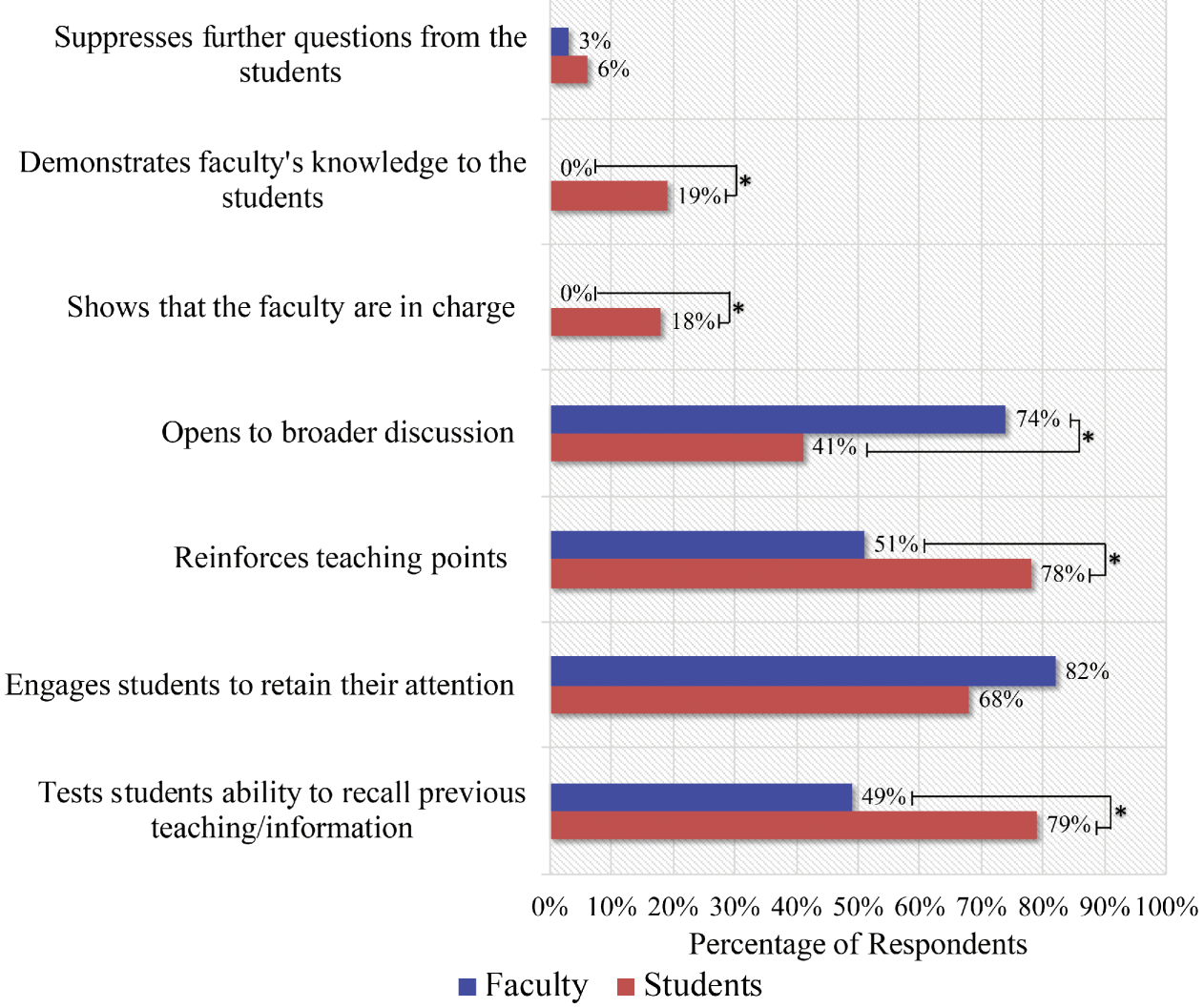

Figure 4. Reason for the Use of Socratic Teaching

Fisher's exact and chi-square tests performed on groups. Student responses, $N=225$; faculty responses, $\mathrm{N}=54$; ${ }^{*}$ denotes significance of $\mathrm{p}<0.01$. 
(20 (51\%) vs $71(78 \%)$, respectively; $\mathrm{p}<0.0001)$ and that it tests students' ability to recall previous teaching/information (19 (49\%) vs 174 (79\%), respectively; $\mathrm{p}<0.0001)$.

\section{Pimping Versus Perceived Role on the Clinical Team}

A majority of students report their role on the clinical care team as insignificant: $86(38 \%)$ reported their role as observer, and 117 (52\%) responded that the team would be minimally impacted by their absence. Were their role on the team more significant, 92 (41\%) reported that pimping would feel more as learning, while only 9 (4\%) reported that it would feel less as learning, and 47 (21\%) reported that it would feel less as mistreatment versus only 16 (7\%) who responded that it would feel more as mistreatment ( $p<0.001)$. Nearly half, 101 (45\%), stated that there would be no change in their view of pimping if their role on the team were more significant. In this regard, if the student's role on the team were more significant, approximately 10 times more students would view pimping as learning and 3 times more students would view pimping less as harassment. When analyzing the converse, whether pimping made students feel more a part of the team, $70(31 \%)$ stated that it did, 27 (12\%) stated that it made them feel less a part of the team, and the remainder reported that it did not change their perceived role on the team $(\mathrm{p}<0.001)$.

\section{Alternatives to Pimping}

The majority of students $(153 ; 68 \%)$ were not able to suggest any better alternative to pimping as it is presently used. Seventy-two student respondents (32\%) did suggest an alternative. The most common suggestion was to use pimping with the addition of prior notification on the subject.

\section{Discussion}

Over the past few decades, there has been increased attention on pimping, medical student mistreatment, and their potential relationship. ${ }^{1,4-7,10,19}$ Several authors advise against the use of pimping, citing a negative impact on students and possibly even patients. ${ }^{24-26}$ At our own institution, faculty have reported being informally advised against the use of pimping for fear of its perception as mistreatment. Our student respondents represent a reasonable sample of the target population of medical students in the state of Michigan (24\% of all fourth-year students). With regard to gender, female students were slightly overrepresented in our sample. Based on age and race/ethnicity, this sample is representative of the population in general, given the best available comparison data. ${ }^{27}$

In our sample, $70 \%$ of medical students agreed with how we defined "pimping," and $100 \%$ of students had experienced it as defined. This helps to solidify the definition as teaching by questioning the student on the subject at hand. The vast majority of students had experienced pimping in group and individual settings either on a daily or weekly basis. Over half of the sample responded that pimping should be used consistently. This is similar to data from Zou et al, ${ }^{28}$ who found that the majority of students prefer to learn in a more active context. This is in direct contrast to only a minority of the faculty respondents who stated that pimping should be used consistently. This suggests that while most students would like this form of teaching, faculty are reluctant to use it. However, given how often medical students report experiencing and witnessing pimping, faculty may use this modality more than reported. 
Interestingly, there were more female than male student respondents $(\mathrm{p}<0.0001)$. While we found no significant difference in frequency or positive/negative perception of pimping based on gender, this does raise the question whether there is a gender-related difference in the use or impact of pimping. Higher survey response rates may be an indicator of level of interest in the survey topic. If this is the case, it may be worthwhile for similar studies to investigate the gender disparities with regard to pimping within the clinical education environment.

Students in our study described pimping more commonly as "challenging" and "educational" and less often as "prideful" and "humiliating," suggesting that students find pimping stressful yet recognize it as educational. This is in contrast to Williams et al, ${ }^{24}$ who reported it being "intimidating," "stressful," and "embarrassing." Furthermore, we found a discrepancy between student and faculty perceptions of the purpose of pimping. While the majority of students believed pimping was used to reinforce teaching points and test the ability to recall information, a minority perceived pimping as faculty demonstrating their knowledge or reinforcing the power differential that exists within the team. A majority of faculty responded that their intent was to open broader discussions and engage students. Therefore, educational benefits may coexist with the malevolent elements classically associated with pimping. Our data suggest that education regarding pimping for both students and faculty, rather than banning or strongly discouraging it, would be beneficial.

The majority of students could not suggest a better alternative to pimping. For those who could, the most common suggestion was informing students about the topic on which they would be questioned. Another suggestion was using more group-based questioning in which volunteers are requested instead of calling on a specific student. While it is reasonable in many circumstances to allow students time to prepare for a subject or ask for volunteer responders, it is important to acknowledge that these accommodations may not be possible or appropriate in all clinical teaching scenarios.

We had hypothesized that students' perception of the importance of their role on the clinical care team would vary indirectly with their perception of pimping as mistreatment. Our data supported this. If given an increased role on the care team, 10 times more students reported that they would view pimping more as learning, and 3 times more students would view pimping less as harassment. Less than half of students (45\%) stated that their perceptions of pimping would not change if their role on the care team were increased. In the present study, medical students most commonly reported that their role as a member of the care team was "minimal," as an observer, or that, if the student were absent, the team would be minimally impacted, and responses regarding their perception of pimping as mistreatment did not vary based on this. Interestingly, however, post hoc we examined the reverse and found that as pimping increased, the number of students who felt more a part of the care team $(70 ; 31 \%)$ was greater than that of those who felt less a part of the team $(27 ; 12 \%)(\mathrm{p}<0.0001)$. These data demonstrate an area of opportunity for addressing medical student mistreatment and provide an avenue for faculty development.

\section{Limitations}

This study has several limitations. There is an inherently negative connotation to the term "pimping" within the medical community. While we attempted to minimize this bias by using the term "Socratic teaching," some negative bias was still likely present. Our sample was limited to medical schools within the state of Michigan, which may limit the generalizability of our findings. However, the multiple medical schools within Michigan span a range of clinical settings from academic tertiary care to community hospitals, within both large urban communities 
and more suburban ones, which broadens the demographic range to some degree. Furthermore, this study is limited by only a modest response from faculty.

\section{Conclusion}

This study begins to shed light on whether pimping is a contributing factor in medical student mistreatment reported by the AAMC GQ. Our data suggest pimping is a positive experience for the majority of the medical students in the state of Michigan. There are some differences in student and faculty perceptions of pimping, with faculty believing it opens to broader discussion and some students believing it is a demonstration of authority. Students' perceived role or importance on the health care team did not influence their perception of pimping as mistreatment. Elimination of pimping in clinical education may have significant consequences, with students feeling less a part of the health care team, having less reinforcement of information, and developing poorer recall rates. Moreover, faculty may be further restricted in terms of engaging, educating, and communicating clinical knowledge. Although more specific research is still needed, our initial data do not support elimination of pimping as a means of reducing medical student mistreatment and instead suggest there may a benefit: pimping makes more students feel included in the care team. Possible gender differences in the experience or perception of pimping deserve further investigation.

\section{Acknowledgments}

None.

\section{References}

1. Dickstein L. Appropriate Treatment in Medicine (ATM): A Compendium on Medical Student Mistreatment: A Project of the AAMC Group on Student Affairs. Association of American Medical Colleges; 2000.

2. Haviland MG, Yamagata H, Werner LS, Zhang K, Dial TH, Sonne JL. Student mistreatment in medical school and planning a career in academic medicine. Teach Learn Med. 2011;23(3): 231-237. doi:10.1080/10401334.2011.586914

3. Uhari M, Kokkonen J, Nuutinen M, et al. Medical student abuse: an international phenomenon. JAMA. 1994;271(13):1049-1051. doi:10.1001/jama.271.13.1049

4. Silver HK, Glicken AD. Medical student abuse: incidence, severity, and significance. JAMA. 1990;263(4):527-532. doi:10.1001/jama.1990.03440040066030

5. Cook AF, Arora VM, Rasinski KA, Curlin FA, Yoon JD. The prevalence of medical student mistreatment and its association with burnout. Acad Med.2014;89(5):749-754. doi:10.1097/ ACM.0000000000000204

6. Rees CE, Monrouxe LV. "A morning since eight of just pure grill": a multischool qualitative study of student abuse. Acad Med.2011;86(11):1374-1382. doi:10.1097/ACM.0b013e3182303c4c

7. Frank E, Carrera JS, Stratton T, Bickel J, Nora LM. Experiences of belittlement and harassment and their correlates among medical students in the United States: longitudinal survey. BMJ. 2006;333(7570):682. doi:10.1136/bmj.38924.722037.7C

8. Richman JA, Flaherty JA, Rospenda KM, Christensen ML. Mental health consequences and correlates of reported medical student abuse. JAMA.1992;267(5):692-694. doi:10.1001/ jama.1992.03480050096032

9. Dyrbye LN, Thomas MR, Shanafelt TD. Medical student distress: causes, consequences, and proposed solutions. Mayo Clin Proc. 2005;80(12):1613-1622. doi:10.4065/80.12.1613 
10. Brancati FL. The art of pimping. JAMA. 1989;262(1):89-90. doi:10.1001/jama.1989.03430010101039

11. Neville AJ. In the age of professionalism, student harassment is alive and well. Med Educ. 2008;42(5):447-448. doi:10.1111/j.1365-2923.2008.03033.x

12. Stoddard HA, O'Dell DV. Would Socrates have actually used the "Socratic method" for clinical teaching? J Gen Intern Med. 2016;31(9):1092-1096. doi:10.1007/s11606-016-3722-2

13. Wiebe C. Medical student "hazing" is unhealthy and unproductive. MedGenMed.2007;9(2):60.

14. Oh RC, Reamy BV. The Socratic method and pimping: optimizing the use of stress and fear in instruction. Virtual Mentor. 2014;16(3):182-186. doi:10.1001/virtualmentor.2014.16.03.medu2-1403

15. Oh RC. The Socratic method in medicine-the labor of delivering medical truths. Fam Med. 2005;37(8):537-539.

16. Vaughn L, Baker R. Teaching in the medical setting: balancing teaching styles, learning styles and teaching methods. Med Teach. 2001;23(6):610-612. doi:10.1080/01421590120091000

17. Wear D, Kokinova M, Keck-McNulty C, Aultman J. Pimping: perspectives of 4th year medical students. Teach Learn Med.2005;17(2):184-191.doi:10.1207/s15328015tlm1702_14

18. Slavin SJ, Schindler DL, Chibnall JT. Medical student mental health 3.0: improving student wellness through curricular changes. Acad Med.2014;89(4):573-577. doi:10.1097/ ACM.0000000000000166

19. Farquhar J, Kamei R, Vidyarthi A. Strategies for enhancing medical student resilience: student and faculty member perspectives. Int J Med Educ. 2018;9:1-6. doi:10.5116/ijme.5a46.1ccc

20. Lyndon MP, Henning MA, Alyami H, Krishna S, Yu T-C, Hill AG. The impact of a revised curriculum on academic motivation, burnout, and quality of life among medical students. J Med Educ Curric Dev. 2017;4:2382120517721901. doi:10.1177/2382120517721901

21. Fleit HB, Iuli RJ, Fischel JE, Lu W-H, Chandran L. A model of influences on the clinical learning environment: the case for change at one U.S. medical school. BMC Med Educ. 2017;17(1):63. doi:10.1186/s12909-017-0900-9

22. Wasson LT, Cusmano A, Meli L, et al. Association between learning environment interventions and medical student well-being: a systematic review. JAMA. 2016;316(21):2237-2252. doi:10.1001/jama.2016.17573

23. Williams EA, Miesner AR, Beckett EA, Grady SE. "Pimping” in pharmacy education: a survey and comparison of student and faculty views.J Pharm Pract. 2018;31(3):353-360. doi:10.1177/0897190017715393

24. McCarthy CP, McEvoy JW. Pimping in medical education: lacking evidence and under threat. JAMA. 2015;314(22):2347-2348. doi:10.1001/jama.2015.13570

25. Anderson J. Can "pimping" kill? The potential effect of disrespectful behavior on patient safety. JAAPA. 2013;26(4):53, 56. doi:10.1097/01720610-201304000-00014

26. Kost A, Chen FM. Socrates was not a pimp: changing the paradigm of questioning in medical education. Acad Med. 2015;90(1):20-24. doi:10.1097/ACM.0000000000000446

27. U.S. Medical School Applications and Matriculants by School, State of Legal Residence, and Sex, 20I8-20I9. Association of American Medical Colleges; 2018.

28. Zou L, King A, Soman S, et al. Medical students' preferences in radiology education a comparison between the Socratic and didactic methods utilizing PowerPoint features in radiology education. Acad Radiol.2011;18(2):253-256. doi:10.1016/j.acra.2010.09.005

(c) 2021 Author(s)

This is an open-access article distributed under the terms of the Creative Commons Attribution 4.0 International license, which permits anyone to download, copy, distribute, display, or adapt the text without asking for permission, provided that the creator(s) are given full credit.

ISSN 2470-9727 